\title{
Prevalence and Determinants of Fatigue after COVID-19 in Non-Hospitalized Subjects: A Population-Based Study
}

\author{
Knut Stavem ${ }^{1,2,3, *(D)}$, Waleed Ghanima ${ }^{1,4,5}$, Magnus K. Olsen ${ }^{5}$, Hanne M. Gilboe ${ }^{6}$ and Gunnar Einvik ${ }^{1,3}$ \\ 1 Institute of Clinical Medicine, University of Oslo, 0450 Oslo, Norway; waleed.ghanima@so-hf.no (W.G.); \\ gunnar.einvik@medisin.uio.no (G.E.) \\ 2 Health Services Research Unit, Akershus University Hospital, 1478 Lørenskog, Norway \\ 3 Department of Pulmonary Medicine, Division of Medicine, Akershus University Hospital, \\ 1478 Lørenskog, Norway \\ 4 Department of Medicine, Østfold Hospital Trust, 1714 Grålum, Norway \\ 5 Department of Research, Østfold Hospital Trust, 1714 Grålum, Norway; magnus.kringstad.olsen@so-hf.no \\ 6 Fürst Medical Laboratory, 1051 Oslo, Norway; hmgilboe@furst.no \\ * Correspondence: knut.stavem@medisin.uio.no; Tel.: +47-975-421-57
}

Citation: Stavem, K.; Ghanima, W.; Olsen, M.K.; Gilboe, H.M.; Einvik, G. Prevalence and Determinants of Fatigue after COVID-19 in Non-Hospitalized Subjects: A Population-Based Study. Int. J. Environ. Res. Public Health 2021, 18, 2030. https://doi.org/10.3390/ ijerph18042030

Academic Editor: Paul B. Tchounwou Received: 27 December 2020

Accepted: 16 February 2021

Published: 19 February 2021

Publisher's Note: MDPI stays neutra with regard to jurisdictional claims in published maps and institutional affiliations.

Copyright: (c) 2021 by the authors Licensee MDPI, Basel, Switzerland. This article is an open access article distributed under the terms and conditions of the Creative Commons Attribution (CC BY) license (https:// creativecommons.org/licenses/by/ $4.0 /)$.
Abstract: This study assessed the prevalence and determinants of fatigue in a population-based cohort of non-hospitalized subjects 1.5-6 months after COVID-19. It was a mixed postal/web survey of all non-hospitalized patients $\geq 18$ years with a positive PCR for SARS-CoV-2 until 1 June 2020 in a geographically defined area. In total, 938 subjects received a questionnaire including the Chalder fatigue scale (CFQ-11) and the energy/fatigue scale of the RAND-36 questionnaire. We estimated $\mathrm{z}$ scores for comparison with general population norms. Determinants were analyzed using multivariable logistic and linear regression analysis. In total, 458 subjects (49\%) responded to the survey at median 117.5 days after COVID-19 onset, and $46 \%$ reported fatigue. The mean z scores of the CFQ-11 total was 0.70 (95\% CI 0.58 to 0.82 ), CFQ-11 physical 0.66 (0.55 to 0.78 ), CFQ-11 mental 0.47 (0.35 to 0.59 ) and RAND-36 energy/fatigue -0.20 ( -0.31 to -0.1$)$; all CFQ-11 scores differed from those of the norm population $(p<0.001)$. Female sex, single/divorced/widowed, short time since symptom debut, high symptom load, and confusion during acute COVID-19 were associated with higher multivariable odds of fatigue. In conclusion, the burden of post-viral fatigue following COVID-19 was high, and higher than in a general norm population. Symptoms of fatigue were most prevalent among women, those having a high symptom load, or confusion during the acute phase.

Keywords: COVID-19; fatigue; post-infectious fatigue; prevalence; CFQ-11

\section{Introduction}

Most patients with COVID-19 experience none or only minor upper respiratory symptoms, but respiratory symptoms, such as cough or dyspnea, and non-respiratory symptoms, such as fatigue, tiredness, sleepiness, and headache, are common during the acute phase of COVID-19 [1,2]. In several other infectious diseases such as Epstein-Barr virus, Q fever, Ross River virus, giardiasis, or in community-acquired pneumonia, such symptoms may persist several months after an infection [3,4]. During follow-up in survivors of other coronaviruses, such as severe acute respiratory syndrome (SARS), 64\% reported fatigue at 3 months, 54\% at 6 months, and 60\% at 12 months [5,6]. Following Middle East respiratory syndrome (MERS), 48\% had clinically relevant fatigue after 12 months [7].

There is considerable concern about long-term sequelae following COVID-19 and that the disease will trigger post-viral fatigue syndromes [8-11]. The prevalence of fatigue following hospitalization for COVID-19 ranges from 52 to 70\% at 1-3 months after hospital discharge [12-14]. Although non-hospitalized patients represent a larger patient group, the majority of emerging data concerns hospitalized patients.

In a convenience sample of non-hospitalized subjects, 50-75\% reported symptoms of fatigue during COVID-19 [15], but little information is available with longer follow-up. 
In a recent population-based study, $24 \%$ reported persistence of fatigue at follow-up by telephone [16]. The above studies used single items for assessing fatigue. There is little information available using more comprehensive multi-item questionnaires designed for assessment of fatigue, with the exception of a recent study comprising a combination of admitted patients and outpatients [17], which reported that, overall, 52\% had fatigue as assessed with the Chalder fatigue scale (CFQ-11) [18]. Using such instruments also enables comparison with general population norms, which eases interpretation of fatigue scores.

The objective of this study was to determine the prevalence of fatigue using the CFQ11 in a large population-based cohort of non-hospitalized subjects in Norway, on average 4 months after COVID-19 infection, and to compare with general population norms, as well as determine risk factors for persistent fatigue.

\section{Materials and Methods}

\subsection{Study Design and Population}

This was a cross-sectional mixed-mode survey of a geographical cohort in the catchment areas of two Norwegian hospitals, Akershus University Hospital (Ahus) and Østfold Hospital (ØН), representing about 900,000 inhabitants in 2020 , or $17 \%$ of the population of Norway.

Up to 1 June 2020, we identified 1029 polymerase chain reaction (PCR) SARS-CoV2-positive subjects $\geq 18$ years from the microbiology laboratories of Ahus, $\varnothing \mathrm{H}$, and the largest private microbiology laboratory in the region, Fürst Medical Laboratory. After the exclusion of 91 subjects (Figure 1), 938 were eligible for inclusion in the survey [19].

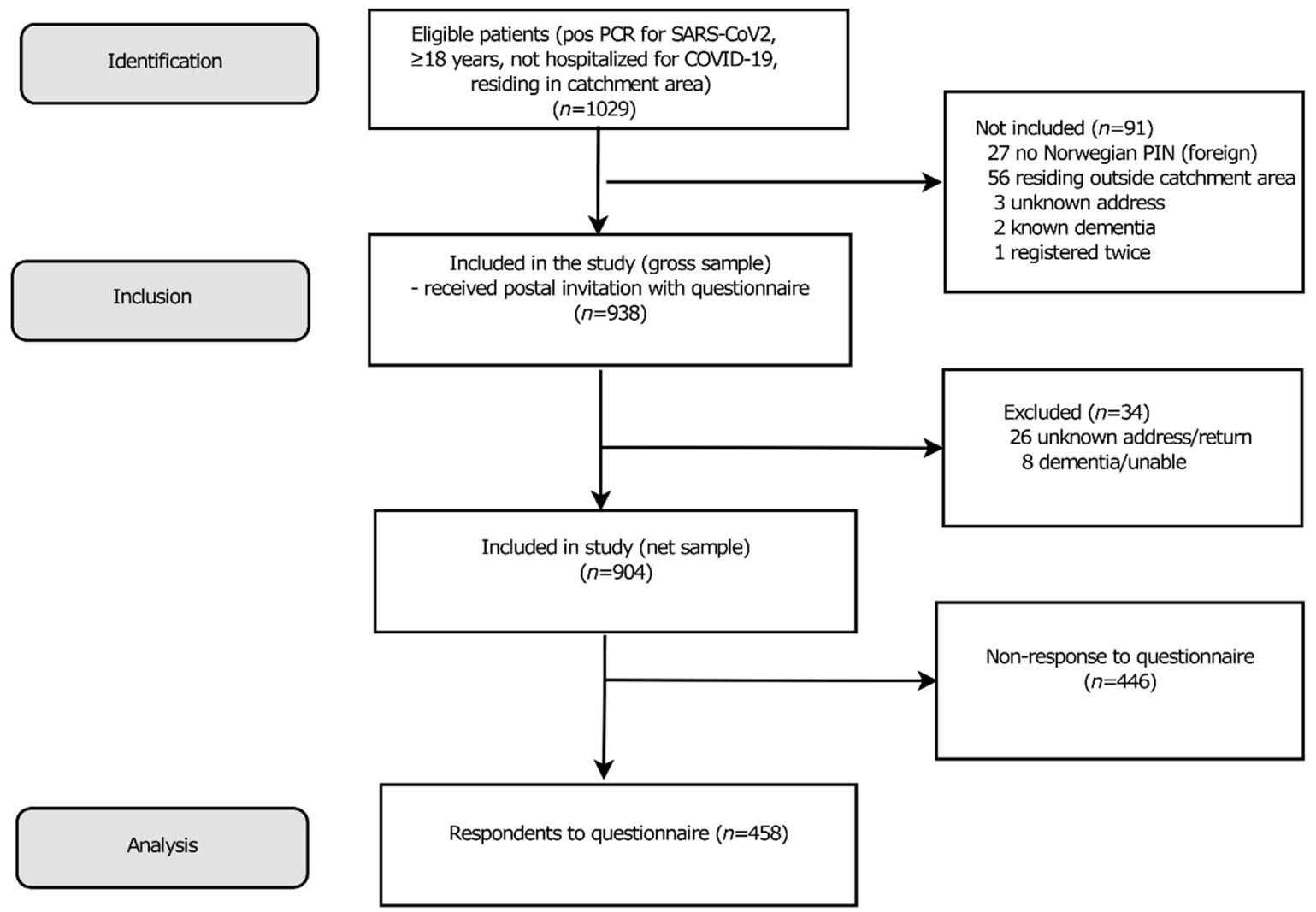

Figure 1. Flow chart showing the selection of the study population.

\subsection{Mixed-Mode Survey and Questionnaire}

The survey started as a postal survey at the end of June, 2020. The subjects were asked to sign a consent form on-line (web-push) by using their personal identification number through a national electronic identification system (ID-porten), and then were forwarded to 
an online web-questionnaire. Alternatively, they could sign the consent form and respond to a paper questionnaire with identical items, which were returned in postage-prepaid envelopes. After about 5 weeks, non-respondents received a postal reminder [19].

The questionnaire contained background information on demographics, education, previous physician-diagnosed disease, recent influenza immunization, date of COVID-19 symptom onset, symptoms during acute COVID-19, current symptoms, height, weight, and standardized questionnaires on health status and fatigue.

\subsection{Assessment of Fatigue}

Fatigue was assessed using the Chalder fatigue scale (CFQ-11) [18]. It contains 11 items on an ordinal 0 to 3 scale, which are summed to a total score (range 0-33; 33 denotes maximal symptoms) and two subscales: physical fatigue (seven items, range 0-21) and mental fatigue (four items, range 0-12). The CFQ-11 also has an alternative scoring algorithm, bimodal scoring, where each item response is dichotomized; 0 (0 to 1) or 1 ( 2 to 3 ) and summed to a $0-11$ scale. Conventionally, fatigue case-status (fatigued vs. non-fatigued) is defined using this scale with a cut-off at $<4$ vs. $\geq 4[18,20]$.

We assessed health status using the RAND-36 questionnaire [21]. In this analysis, we used the energy/fatigue scale of this questionnaire as a marker of fatigue [22]. It consists of four items, and is scored on a 0-100 scale, where 100 denotes maximal health.

\subsection{Assessment of Comorbidity and COVID-19 Symptoms}

Comorbidity was recorded using a checklist of 21 physician-diagnosed problems, 18 of which constituted a self-reported version of the Charlson comorbidity index [23,24] and some additional items of relevance in COVID-19. We categorized this comorbidity index as 0,1 , and $\geq 2$ comorbidity. In addition, we used history of depression separately, as this variable is associated with fatigue $[17,25]$.

As measures of the severity of the acute phase of COVID-19, we used: (1) a symptom score based on 23 self-reported symptoms, not including fatigue, i.e., the total number of self-reported symptoms categorized in tertiles $(0-5,6-9$, and 10-23); (2) presence of dyspnea; and (3) presence of confusion.

\subsection{Statistical Analysis}

Participants' characteristics are presented as mean (SD), median (interquartile range or range) or number (\%), as appropriate. Groups were compared using the $t$-test for continuous, or chi-squared test for categorical, variables.

The prevalence of fatigue was assessed using score $\geq 4$ from bimodal scoring of the CFQ-11 [18] as cut-off. The crude prevalence of fatigue was compared between men and women using the chi-squared test.

In addition, we presented total fatigue score (0-33 range) and two dimension scores, as well as RAND-36 energy/fatigue scores as continuous scores. We calculated z scores for each participant on these scales, providing the fatigue level for each participant in comparison to mean and SD in the matching age- and sex-specific stratum in normative data from Norwegian general populations $[20,26]$. The $z$ score represents the difference from the mean of the norm population, reported in number of SDs.

Determinants of fatigue (dichotomized CFQ- 11 bimodal score, $<4$ vs. $\geq 4$ ) were analyzed using multivariable logistic regression. Determinants of fatigue scores (CFQ-11 total, Likert scoring) and the Energy/fatigue scale of the RAND-36 were analyzed using multiple linear regression analysis.

We included the following independent variables in the models, based on the literature and what we thought might be important: age/10, sex, education (three levels), marital status (married/cohabiting vs. single/widowed), body mass index (BMI) $\left(\mathrm{kg} / \mathrm{m}^{2}\right)$, number of self-reported comorbidities, a modification of the Charlson index $(0,1, \geq 2)$, smoking status (current/previous vs. never smoker), history of depression (yes vs. no), number of symptoms during acute COVID-19 (0-5, 6-9, 10-23), and dyspnea (yes vs. no) or confusion 
(yes vs. no) during COVID-19, as well as time since symptom onset during COVID-19 (tertiles; 41-109, 110-126, 127-182 days). All variables were entered into the multivariable models without any statistical variable selection procedure. As there were few missing values, we used complete case analysis.

We used Stata (version 16.1, Stata Corporation, College Station, TX, USA) for all statistical analyses, and chose a $5 \%$ a significance level.

\section{Results}

\subsection{Study Population}

In total, 458 subjects ( $49 \%$ of the gross sample, $51 \%$ of the net sample) completed the questionnaire (Figure 1). The respondents were older (mean age on 1 June 202049.5 (SD 15.3) vs. $43.9(17.3)$ years, $p<0.001)$ and comprised a larger proportion of women $(256(56 \%)$ vs. $219(46 \%), p=0.005)$, than non-respondents in the gross sample.

Respondents' characteristics are shown in Table 1. The subjects responded to the questionnaires a median 117.5 days (25th to 75th percentile 105-135, range 41-200) after first symptom of COVID-19. In total, 117 (26\%) of the respondents had contracted COVID19 during travel abroad.

Table 1. Respondent characteristics $(n=458)$. Number $(\%)$, unless specified otherwise.

\begin{tabular}{|c|c|}
\hline Age, Mean (Range) & $49.6(17.7$ to 87.9$)$ \\
\hline Sex, female & $256(56)$ \\
\hline \multicolumn{2}{|l|}{ Marital status } \\
\hline Single/divorced/separated/widowed & $121(26)$ \\
\hline Married/cohabiting & $336(74)$ \\
\hline Born in Norway $(n=457)$ & $382(84)$ \\
\hline Norwegian mother tongue $(n=455)$ & $382(84)$ \\
\hline Both parents born in Norway $(n=434)$ & $357(78)$ \\
\hline \multicolumn{2}{|l|}{ Highest attainted education } \\
\hline Primary school & $41(9)$ \\
\hline Secondary school & $174(38)$ \\
\hline University & $243(53)$ \\
\hline \multicolumn{2}{|l|}{ Smoking status $(n=453)$} \\
\hline Never smoker & $298(66)$ \\
\hline Former/current smoker & $155(34)$ \\
\hline Body mass index $(\mathrm{kg} / \mathrm{m} 2)(n=450)$ & $26.8(5.2)$ \\
\hline Influenza vaccination 2 nd half of $2019(n=456)$ & $141(31)$ \\
\hline \multicolumn{2}{|l|}{ No. of 21 comorbidities, categorized } \\
\hline 0 & $234(51)$ \\
\hline 1 & $129(28)$ \\
\hline$\geq 2$ & $95(21)$ \\
\hline Diabetes & $16(3)$ \\
\hline Pulmonary disease (asthma, COPD, other) & $60(13)$ \\
\hline Depression & $30(7)$ \\
\hline Cardiovascular (heart, hypertension, vascular) & $101(22)$ \\
\hline \multicolumn{2}{|l|}{ Test lab } \\
\hline Akershus University Hospital & $233(51)$ \\
\hline Fürst Laboratory & $61(13)$ \\
\hline Østfold Hospital & $164(36)$ \\
\hline
\end{tabular}

$\overline{\mathrm{COPD}}=$ chronic obstructive pulmonary disease.

During the acute COVID-19 episode, the most common symptoms were fever (73\%), loss/disturbance of taste (70\%), dry cough (67\%), headache (67\%), and loss/disturbance of smell (66\%). When aggregating the symptoms, 106 (23\%) had 0-5 symptoms, $176(38 \%)$ 6-10, and $176(38 \%)$ 10-23. 


\subsection{Prevalence and Symptoms of Fatigue}

The mean CFQ-11 bimodal score was 3.9 (SD 3.7) $(n=458)$; $246(54 \%)$ scored $0-3$ and $212(46 \%)$ scored $4-11$, corresponding to a case-definition of fatigue. Among women, $142(55 \%)$ scored $4-11$, compared with $70(35 \%)$ among men $(p<0.001)$.

On the CFQ-11 with Likert scoring $(n=456)$, the mean total score ( $0-33$ scale) was 15.1 (SD 5.0), the physical subscale (0-21 range) 10.1 (3.8), and mental subscale (0-12 range) 5.0 (1.8). The mean RAND-36 energy/fatigue scale score (0-100 range) was 56.8 (23.9) $(n=457)$.

The mean z scores of the CFQ-11 total was 0.70 (95\% CI 0.58 to 0.82 ), CFQ-11 physical 0.66 (0.55 to 0.78 ), CFQ-11 mental 0.47 (0.35 to 0.59), and RAND-36 energy/fatigue -0.20 $(-0.31$ to -0.10$)$, and all $\mathrm{z}$ scores were different from the norm population, i.e., different from $0(p<0.001)$ (Figure 2).
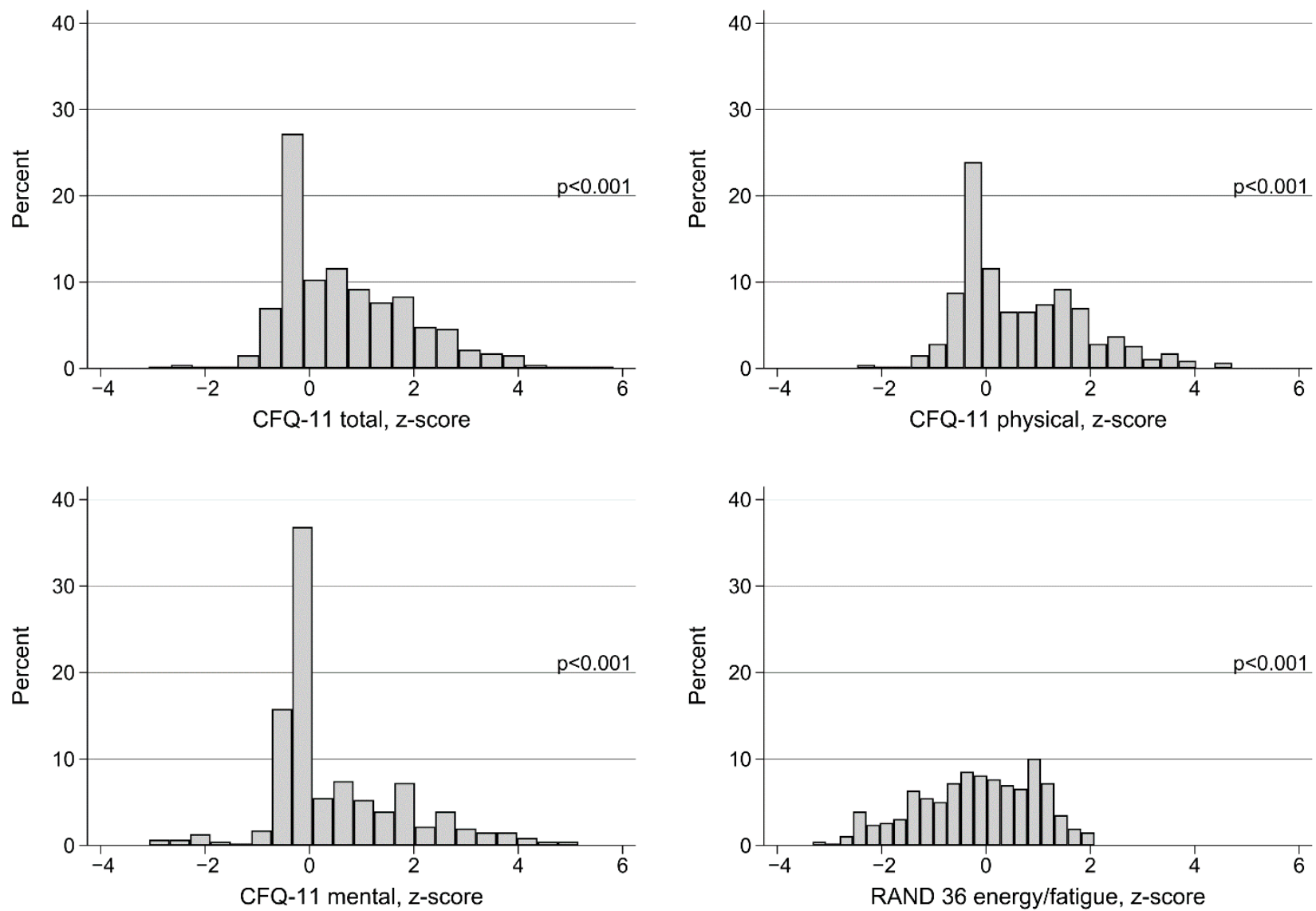

Figure 2. Fatigue and energy/fatigue scores at 1.5-6 months after start of COVID-19, z scores for comparison with age and sex-stratified normative data from Norwegian general populations. CFQ-11 = Chalder fatigue questionnaire. $p$-values are for comparison with $\mathrm{z}$ score $=0$ ( $t$-test).

\subsection{Determinants of Fatigue}

In multivariable logistic regression analysis with fatigue (CFQ-11 bimodal score $\geq 4$ ) as the dependent variable, male sex, being married/cohabiting, and longer time since symptom debut were associated with lower odds of fatigue at the time of the survey than the referents. In contrast, those with a higher symptom load during acute COVID-19 or confusion as a symptom had higher odds of persistent fatigue (Table 2).

In the multivariable regression analysis with CFQ-11 Likert scale score as the dependent variable, males had less fatigue symptoms, while previous depression, high symptom load during COVID-19, dyspnea during COVID-19, and confusion during COVID-19 had 
more fatigue symptoms at the time of the survey than those in the reference categories (Table 3).

Similarly, male sex and $>127$ days since symptom debut were associated with better health status on the energy/fatigue scale of the RAND-36, while higher BMI, previous depression, higher symptom load, dyspnea during COVID-19, and confusion during COVID-19 were indicators of worse health status than those in the reference categories.

Table 2. Determinants of fatigue (defined as CFQ-11 bimodal score, $>3$ vs. $0-3$ ), multivariable logistic regression analysis $(n=440)$.

\begin{tabular}{|c|c|c|c|c|}
\hline Variable & $n$ & Odds Ratio & 95\% Confidence Interval & $p$ \\
\hline Age, per 10 years & 440 & 1.02 & $(0.86$ to 1.22$)$ & 0.81 \\
\hline \multicolumn{5}{|l|}{ Sex } \\
\hline Female * & 245 & 1 & & \\
\hline Male & 195 & 0.49 & $(0.31$ to 0.76$)$ & 0.002 \\
\hline \multicolumn{5}{|l|}{ Marital status } \\
\hline Single/separated/divorced/widowed * & 112 & 1 & & \\
\hline Married/cohabiting & 328 & 0.56 & $(0.34$ to 0.92$)$ & 0.022 \\
\hline \multicolumn{5}{|l|}{ Highest attained educational level } \\
\hline Primary school ( $\leq 11$ years) & 37 & 1 & & \\
\hline Secondary school (12-13 years) & 165 & 1.22 & $(0.54$ to 2.74$)$ & 0.64 \\
\hline University level & 238 & 1.17 & $(0.53$ to 2.61$)$ & 0.70 \\
\hline \multicolumn{5}{|l|}{ No. of comorbidities (out of 21) } \\
\hline 0 * & 223 & 1 & & \\
\hline 1 & 123 & 1.62 & (0.94 to 2.77$)$ & 0.080 \\
\hline$\geq 2$ & 94 & 1.52 & (0.77 to 3.03$)$ & 0.23 \\
\hline \multicolumn{5}{|l|}{ Previous depression } \\
\hline $\mathrm{No}^{*}$ & 412 & 1 & & \\
\hline Yes & 28 & 1.10 & (0.43 to 2.82$)$ & 0.84 \\
\hline \multicolumn{5}{|l|}{ No. of COVID-19 symptoms } \\
\hline $0-5 *$ & 101 & 1 & & \\
\hline $6-9$ & 168 & 1.44 & (0.79 to 2.64$)$ & 0.24 \\
\hline $10-23$ & 171 & 3.66 & (1.88 to 7.11$)$ & $<0.001$ \\
\hline \multicolumn{5}{|l|}{ Dyspnea during COVID-19 } \\
\hline $\mathrm{No}^{*}$ & 190 & 1 & & \\
\hline Yes & 250 & 1.56 & (0.97 to 2.53$)$ & 0.069 \\
\hline \multicolumn{5}{|l|}{ Confusion during COVID-19 } \\
\hline $\mathrm{No}^{*}$ & 381 & 1 & & \\
\hline Yes & 59 & 2.25 & (1.12 to 4.51$)$ & 0.022 \\
\hline Body mass index, $\mathrm{kg} / \mathrm{m}^{2}$ & 440 & 1.03 & (0.99 to 1.08$)$ & 0.13 \\
\hline \multicolumn{5}{|l|}{ Smoking status } \\
\hline Never smoker * & 291 & 1 & & \\
\hline Former/current smoker & 149 & 1.34 & (0.85 to 2.13$)$ & 0.21 \\
\hline \multicolumn{5}{|l|}{ Time since symptom onset, days } \\
\hline $41-110 *$ & 144 & 1 & & \\
\hline $111-127$ & 152 & 0.80 & $(0.47$ to 1.36$)$ & 0.41 \\
\hline $128-200$ & 144 & 0.55 & (0.32 to 0.96$)$ & 0.034 \\
\hline
\end{tabular}

* Baseline category. CFQ-11 = Chalder fatigue questionnaire.

Table 3. Determinants of fatigue scores, (1) CFQ-11 total score (0-33 scale) ${ }^{a}$ and (2) RAND-36 energy/fatigue scale score $(0-100 \text { scale })^{b}$, multiple linear regression analysis.

\begin{tabular}{ccccccc}
\hline Variable & \multicolumn{3}{c}{ CFQ-11 Total Score $(n=438)$} & & \multicolumn{2}{c}{ RAND-36 Energy/Fatigue $(n=440)$} \\
\cline { 2 - 6 } & Coef. & 95\% Confidence Interval & $p$ & Coef. & 95\% Confidence Interval & $p$ \\
\hline $\begin{array}{c}\text { Age, per 10 years } \\
\text { Sex }\end{array}$ & 0.1 & $(-0.24$ to 0.44$)$ & 0.56 & 1.51 & $(-0.05$ to 3.07$)$ & 0.057 \\
$\begin{array}{c}\text { Female } \\
\text { Male }\end{array}$ & 0 & & & 0 & & $(5.58$ to 13.69$)$ \\
$\begin{array}{c}\text { Marital status } \\
\text { Single/separated/divorced/widowed * } \\
\text { Married/cohabiting }\end{array}$ & -1.78 & $(-2.66$ to -0.90$)$ & $<0.001$ & 9.63 & $<0.001$ \\
\hline
\end{tabular}


Table 3. Cont.

\begin{tabular}{|c|c|c|c|c|c|c|}
\hline \multirow{2}{*}{ Variable } & \multicolumn{3}{|c|}{ CFQ-11 Total Score $(n=438)$} & \multicolumn{3}{|c|}{ RAND-36 Energy/Fatigue $(n=440)$} \\
\hline & Coef. & 95\% Confidence Interval & $p$ & Coef. & 95\% Confidence Interval & $p$ \\
\hline \multicolumn{7}{|l|}{ Highest attained educational level } \\
\hline Primary school (<11 years) & 0 & & & 0 & & \\
\hline Secondary school (12-13 years) & 0.03 & $(-1.55$ to 1.62$)$ & 0.97 & 3.98 & $(-3.37$ to 11.33$)$ & 0.29 \\
\hline University level & -0.03 & $(-1.58$ to 1.52$)$ & 0.97 & 4.42 & $(-2.77$ to 11.62$)$ & 0.23 \\
\hline \multicolumn{7}{|l|}{ No. of comorbidities (out of 21) } \\
\hline $0 *$ & 0 & & & 0 & & \\
\hline 1 & 0.48 & $(-0.57$ to 1.53$)$ & 0.37 & -1.35 & $(-6.24$ to 3.54$)$ & 0.59 \\
\hline$\geq 2$ & 0.22 & $(-1.13$ to 1.57$)$ & 0.75 & -6.11 & $(-12.35$ to 0.14$)$ & 0.055 \\
\hline \multicolumn{7}{|l|}{ Previous depression } \\
\hline $\mathrm{No}^{*}$ & 0 & & & 0 & & \\
\hline Yes & 2.38 & (0.57 to 4.18$)$ & 0.010 & -12.05 & $(-20.43$ to -3.68$)$ & 0.005 \\
\hline \multicolumn{7}{|l|}{ No. of COVID-19 symptoms } \\
\hline $0-5 *$ & 0 & & & 0 & & \\
\hline $6-9$ & 0.70 & $(-0.44$ to 1.85$)$ & 0.23 & -8.28 & $(-13.58$ to -2.98$)$ & 0.002 \\
\hline $10-23$ & 2.68 & $(1.38$ to 3.99$)$ & $<0.001$ & -15.59 & $(-21.64$ to -9.55$)$ & $<0.001$ \\
\hline \multicolumn{7}{|l|}{ Dyspnea during COVID-19 } \\
\hline $\mathrm{No}^{*}$ & 0 & & & 0 & & \\
\hline Yes & 1.24 & $(0.29$ to 2.19$)$ & 0.010 & -6.12 & $(-10.53$ to -1.72$)$ & 0.007 \\
\hline \multicolumn{7}{|l|}{ Confusion during COVID-19 } \\
\hline $\mathrm{No}^{*}$ & 0 & & & 0 & & \\
\hline Yes & 2.65 & (1.34 to 3.97$)$ & $<0.001$ & -7.35 & $(-13.44$ to -1.26$)$ & 0.018 \\
\hline Body mass index, $\mathrm{kg} / \mathrm{m}^{2}$ & 0.04 & $(-0.04$ to 0.12$)$ & 0.33 & -0.50 & $(-0.88$ to -0.12$)$ & 0.010 \\
\hline \multicolumn{7}{|l|}{ Smoking status } \\
\hline Never smoker* & 0 & & & 0 & & \\
\hline Former/current smoker & 0.66 & $(-0.25$ to 1.56$)$ & 0.15 & -3.91 & $(-8.10$ to 0.28$)$ & 0.068 \\
\hline \multicolumn{7}{|l|}{ Time since symptom onset, days } \\
\hline $41-110$ * & 0 & & & 0 & & \\
\hline $111-127$ & -0.56 & $(-1.60$ to 0.47$)$ & 0.28 & 1.38 & $(-3.40$ to 6.17$)$ & 0.57 \\
\hline $128-200$ & -0.41 & $(-1.47$ to 0.64$)$ & 0.44 & 6.09 & (1.20 to 10.99$)$ & 0.015 \\
\hline
\end{tabular}

${ }^{*}$ Baseline category. CFQ-11 = Chalder fatigue questionnaire; Coef. = Unstandardized beta coefficient; ${ }^{a}$ Higher values mean more symptoms, ${ }^{b}$ Higher values denote better health status.

\section{Discussion}

In this study of non-hospitalized subjects, $46 \%$ of respondents reported fatigue about 4 months after symptom onset of COVID-19, which represents a substantially higher prevalence than in the norm population [20]. Fatigue was lower among males and higher with high symptom load and confusion during acute COVID-19 on three different fatigue scales. Moreover, previous depression, dyspnea during COVID 19, and higher BMI were associated with more fatigue on two of the scales. Finally, on two of the three scales, caseness of fatigue and symptoms of fatigue were lower among those with the longest follow up since symptom onset, than among referents.

The prevalence of fatigue in the present study was about twice as high as the $22 \%$ reported in a Norwegian general population, also using the CFQ-11 with the same cut-off to denote fatigue [20]. The continuous symptom scores in the present study were worse than in the same norm population, as illustrated by the $\mathrm{z}$ scores.

Fatigue is a common symptom in the general population, as well as in patients with acute or chronic diseases. It is poorly understood, and there is no consensus on its definition or causal mechanism [27]. There is wide variation in the prevalence of fatigue between studies depending on assessment methods, and thresholds, for fatigue $[25,28,29]$. There are numerous validated measures for assessment of fatigue [30], including the CFQ-11 used in the present study. However, some surveys after COVID-19 have used simple checklists, such as being asked to recount the presence or absence of symptoms, where fatigue was one of the symptoms, i.e., the presence of fatigue is indicated by the response to one yes/no item $[13,31,32]$. Therefore, assessments between studies may be difficult to compare.

There have been few studies on COVID-19 using standardized multi-item scales for assessing fatigue. We are only aware of one other community-based study, which used the fatigue impact scale and reported a prevalence of $24 \%$, which is lower than in the present study, although it is not clear whether the prevalence numbers were from using this scale 
or a single item on fatigue [16]. The prevalence of fatigue in the present study was slightly lower than that reported in hospitalized and non-hospitalized individuals recovered from the acute phase of COVID-19 illness, where $52 \%$ reported persistent fatigue at a median of 10 weeks after initial symptoms of COVID-19 [17]. That study used the CFQ-11 and the same cut-off for defining fatigue as in the present study. Another study, using another multi-item scale, reported a prevalence of $53 \%$ about 4 weeks after hospitalization for COVID-19 [33], and in a third study $69 \%$ of respondents reported fatigue on the Nijmegen clinical screening instrument at 3 months after hospitalization for acute COVID-19 [34].

A few other studies have used single items to assess fatigue following COVID-19, generally reporting higher prevalence of fatigue than in our study [12-14,32]. However, differences in populations, methods, and timing relative to the acute phase complicates comparisons between studies. Fatigue was reported by $60-70 \%$ on average 48 days after hospital discharge [12], and by $53 \%$ of hospitalized patients on average 36 days after discharge (60 days after symptom start) $(n=143)$ [13]. In a large web-recruited population with hospitalized and non-hospitalized subjects after COVID-19 [32], 87\% reported current fatigue on average 79 days after COVID-19, in a population mainly consisting of women. This finding of enduring fatigue, however, is not universal. For example, another study reported resolution of fatigue 3-4 weeks after discharge from hospital, although the number of subjects with fatigue was small [35]. Slow resolution of symptoms and persistent fatigue is not unique to COVID-19, as this has been reported following other infectious diseases, such as community-acquired pneumonia or SARS [36-38].

In the present study, persistent fatigue was associated with female sex, high symptom load, and confusion during acute COVID-19, as well as indications of an association with previous depression, dyspnea, and BMI. This supports and expands on previous findings that persistent fatigue following COVID-19 is associated with female sex and pre-existing depression/anxiety [17]. The latter study did not find an association of fatigue with time since symptom onset, which contrasts with the present study. This difference may be attributed to differences in populations, severity of disease, or length of the observation period.

Fatigue in the general population was more prevalent in women than in men in some studies [20,25], but not in others [28]. The association of fatigue with age has also been inconsistent $[20,28]$. Following SARS, those with fatigue symptoms after $>6$ months were more likely to have comorbid active psychiatric disorders [39]. Whether this applies to COVID-19 remains to be seen.

Some strengths of this study should be noted. The present study was large and was conducted in a geographical area comprising about $17 \%$ of the Norwegian population. As GPs and hospitals in the catchment area mainly use the three laboratories in the study, we anticipate that these labs will have analyzed $>90 \%$ of the samples for SARS-CoV-2 in the two hospitals' catchment populations. However, some patients may have been diagnosed in other laboratories during travel to other regions. As the study was populationbased, it is more representative of the total population of non-hospitalized COVID-19 survivors than convenience samples, which increases the external validity of the findings. Other strengths are the comparison with general population norms, which facilitates interpretation of the scores, and that we used multivariable analysis, adjusting for several possible confounding variables.

Several limitations of the study should be noted. The overall response rate was about $50 \%$, which we consider good for a population-based survey, and in line with a priori expectations. The response rate was higher than in some recent Norwegian large health surveys of 33-36\%, using similar questionnaires in general populations [29,40]. Studies have shown a pattern of decreasing survey response rate over the past decades, although this depends on the length of the questionnaire, the topic, target population, and whether incentives are used [41-43]. Furthermore, web-surveys tend to have lower response rates than traditional mailed surveys [44].

The responses in our study were somewhat biased towards females and subjects $>50$ years of age. Moreover, the response rate was low in the three districts of Oslo with 
a large proportion of immigrants in the population. Some of this nonresponse may be related to limitations in knowledge of the Norwegian language, as the questionnaire was only available in Norwegian. This pattern of nonresponse is common in epidemiological surveys [29,41], and may cause nonresponse bias, which is difficult to control for and may limit generalizability. Responses to some of the questions, such as symptoms during COVID-19, may have been influenced by recall bias.

Surveys of the general population during the COVID-19 epidemic have shown a high prevalence of psychological morbidities and considerable distress during the period of lockdown, social distancing, and inability to travel, although with large variations between studies [45-47]. Recent studies have also shown an association between anxiety and somatic symptoms, including fatigue [48], and the World Health Organization has introduced the term "pandemic fatigue" to describe the feeling of distress in the population as a reaction to the prolonged period of uncertainty and crisis during the pandemic [49]. Therefore, in the present study, it is difficult to separate the general impact of the pandemic and the media exposure, from the impact of personal experience of the COVID-19 episode.

The high prevalence of fatigue following even mild cases of COVID-19 may have important consequences for individuals and society, although the observation time of 4 months is short. It is possible that rehabilitation or specific interventions may influence the development of these symptoms, although such interventions ought to be evaluated in randomized controlled trials. Those being most at risk for having persistent fatigue or other symptoms may possibly benefit from a tailored program of follow-up and support. If fatigue is accentuated by the threats of the pandemic, it is also possible that improvement or resolution of symptoms may occur spontaneously over time when the pandemic ends and social distancing eases.

\section{Conclusions}

This study has shown that persistent fatigue is common from 1.5-6 months after COVID-19 in a non-hospitalized population. The findings suggest that fatigue had started tapering off after about 4 months, which is promising. However, whether this represent the start of a long-term resolution of the symptoms should be investigated in longitudinal studies. Female sex, and high symptom load during acute COVID-19, which are nonmodifiable risk factors, were markers of persistent fatigue symptoms.

Author Contributions: Conceptualization, K.S., G.E.; methodology, K.S., G.E, W.G., M.K.O., H.M.G.; formal analysis, K.S.; investigation, K.S., M.K.O., G.E., H.M.G.; software, K.S., data curation, K.S.; Writing-Original draft preparation, K.S.; Writing-Review and editing, K.S., M.K.O., G.E., H.M.G., W.G.; visualization, K.S.; supervision and project administration, K.S., G.E., W.G. All authors have read and agreed to the published version of the manuscript.

Funding: This research received no external funding.

Institutional Review Board Statement: The Regional Committees for Medical and Health Research Ethics, Health Region South East (approval no. 2020/149384) and the Data Protection Officer at Akershus University Hospital approved the study.

Informed Consent Statement: Informed consent was obtained from all subjects involved in the study.

Data Availability Statement: Anonymized data supporting the study findings are available from the corresponding author on reasonable request.

Conflicts of Interest: Ghanima reports personal fees from Novartis, grants from Pfizer, personal fees from Amgen, grants and personal fees from Bayer, personal fees from Sanofi, outside the submitted work; Einvik reports grants from AstraZeneca AS, grants from Boehringer Ingelheim, outside the submitted work. The other authors declare: no support from any organisation for the submitted work; no financial relationships with any organisations that might have an interest in the submitted work in the previous three years; no other relationships or activities that could appear to have influenced the submitted work. 


\section{References}

1. Huang, C.; Wang, Y.; Li, X.; Ren, L.; Zhao, J.; Hu, Y.; Zhang, L.; Fan, G.; Xu, J.; Gu, X.; et al. Clinical features of patients infected with 2019 novel coronavirus in Wuhan, China. Lancet 2020, 395, 497-506. [CrossRef]

2. Docherty, A.B.; Harrison, E.M.; Green, C.A.; Hardwick, H.E.; Pius, R.; Norman, L.; Holden, K.A.; Read, J.M.; Dondelinger, F.; Carson, G.; et al. Features of 20133 UK patients in hospital with covid-19 using the ISARIC WHO Clinical Characterisation Protocol: Prospective observational cohort study. BMJ 2020, 369, m1985. [CrossRef] [PubMed]

3. Salit, I.E. Post-infectious fatigue. Can. Fam. Physician 1987, 33, 1217-1219.

4. Hickie, I.; Davenport, T.; Wakefield, D.; Vollmer-Conna, U.; Cameron, B.; Vernon, S.D.; Reeves, W.C.; Lloyd, A.; Dubbo Infection Outcomes Study Group. Post-infective and chronic fatigue syndromes precipitated by viral and non-viral pathogens: Prospective cohort study. BMJ 2006, 333, 575. [CrossRef]

5. Tansey, C.M.; Louie, M.; Loeb, M.; Gold, W.L.; Muller, M.P.; de Jager, J.; Cameron, J.I.; Tomlinson, G.; Mazzulli, T.; Walmsley, S.L.; et al. One-year outcomes and health care utilization in survivors of severe acute respiratory syndrome. Arch. Intern. Med. 2007, 167, 1312-1320. [CrossRef] [PubMed]

6. O'Sullivan, O. Long-term sequelae following previous coronavirus epidemics. Clin. Med. 2021, 21, e68-e70. [CrossRef]

7. Lee, S.H.; Shin, H.S.; Park, H.Y.; Kim, J.L.; Lee, J.J.; Lee, H.; Won, S.D.; Han, W. Depression as a Mediator of Chronic Fatigue and Post-Traumatic Stress Symptoms in Middle East Respiratory Syndrome Survivors. Psychiatry Investig. 2019, 16, 59-64. [CrossRef]

8. Mahase, E. Covid-19: What do we know about "long covid"? BMJ 2020, 370. [CrossRef]

9. Yelin, D.; Wirtheim, E.; Vetter, P.; Kalil, A.C.; Bruchfeld, J.; Runold, M.; Guaraldi, G.; Mussini, C.; Gudiol, C.; Pujol, M.; et al. Long-term consequences of COVID-19: Research needs. Lancet Infect. Dis. 2020, 20, 1115-1117. [CrossRef]

10. Wilson, C. Concern coronavirus may trigger post-viral fatigue syndromes. New Sci. 2020, 246, 10-11. [CrossRef]

11. Marshall, M. The lasting misery of coronavirus long-haulers. Nature 2020, 585, 339-341. [CrossRef]

12. Halpin, S.J.; McIvor, C.; Whyatt, G.; Adams, A.; Harvey, O.; McLean, L.; Walshaw, C.; Kemp, S.; Corrado, J.; Singh, R.; et al. Postdischarge symptoms and rehabilitation needs in survivors of COVID-19 infection: A cross-sectional evaluation. J. Med. Virol. 2020. [CrossRef]

13. Carfi, A.; Bernabei, R.; Landi, F.; Gemelli Against, C.-P.-A.C.S.G. Persistent Symptoms in Patients After Acute COVID-19. JAMA 2020, 324, 603-605. [CrossRef] [PubMed]

14. Liang, L.; Yang, B.; Jiang, N.; Fu, W.; He, X.; Zhou, Y.; Ma, W.L.; Wang, X. Three-month Follow-up Study of Survivors of Coronavirus Disease 2019 after Discharge. J. Korean Med. Sci. 2020, 35, e418. [CrossRef]

15. Burke, R.M.; Killerby, M.E.; Newton, S.; Ashworth, C.E.; Berns, A.L.; Brennan, S.; Bressler, J.M.; Bye, E.; Crawford, R.; Harduar Morano, L.; et al. Symptom Profiles of a Convenience Sample of Patients with COVID-19—United States, January-April 2020. MMWR Morb. Mortal. Wkly. Rep. 2020, 69, 904-908. [CrossRef]

16. Petersen, M.S.; Kristiansen, M.F.; Hanusson, K.D.; Danielsen, M.E.; Gaini, S.; Strom, M.; Weihe, P. Long COVID in the Faroe Islands-A longitudinal study among non-hospitalized patients. Clin. Infect. Dis. 2020. [CrossRef]

17. Townsend, L.; Dyer, A.H.; Jones, K.; Dunne, J.; Mooney, A.; Gaffney, F.; O’Connor, L.; Leavy, D.; O’Brien, K.; Dowds, J.; et al. Persistent fatigue following SARS-CoV-2 infection is common and independent of severity of initial infection. PLoS ONE 2020, 15, e0240784. [CrossRef] [PubMed]

18. Chalder, T.; Berelowitz, G.; Pawlikowska, T.; Watts, L.; Wessely, S.; Wright, D.; Wallace, E.P. Development of a fatigue scale. J. Psychosom. Res. 1993, 37, 147-153. [CrossRef]

19. Stavem, K.; Ghanima, W.; Olsen, M.K.; Gilboe, H.M.; Einvik, G. Persistent symptoms 1.5-6 months after COVID-19 in nonhospitalised subjects: A population-based cohort study. Thorax 2020. [CrossRef]

20. Loge, J.H.; Ekeberg, O.; Kaasa, S. Fatigue in the general Norwegian population: Normative data and associations. J. Psychosom. Res. 1998, 45, 53-65. [CrossRef]

21. Hays, R.D.; Sherbourne, C.D.; Mazel, R.M. The RAND 36-Item Health Survey 1.0. Health Econ. 1993, 2, $217-227$. [CrossRef] [PubMed]

22. Brown, L.F.; Kroenke, K.; Theobald, D.E.; Wu, J. Comparison of SF-36 vitality scale and Fatigue Symptom Inventory in assessing cancer-related fatigue. Support. Care Cancer 2011, 19, 1255-1259. [CrossRef] [PubMed]

23. Katz, J.N.; Chang, L.C.; Sangha, O.; Fossel, A.H.; Bates, D.W. Can comorbidity be measured by questionnaire rather than medical record review? Med. Care 1996, 34, 73-84. [CrossRef] [PubMed]

24. Charlson, M.E.; Pompei, P.; Ales, K.L.; MacKenzie, C.R. A new method of classifying prognostic comorbidity in longitudinal studies: Development and validation. J. Chronic. Dis 1987, 40, 373-383. [CrossRef]

25. Pawlikowska, T.; Chalder, T.; Hirsch, S.R.; Wallace, P.; Wright, D.J.; Wessely, S.C. Population based study of fatigue and psychological distress. BMJ 1994, 308, 763-766. [CrossRef]

26. Garratt, A.M.; Stavem, K. Measurement properties and normative data for the Norwegian SF-36: Results from a general population survey. Health Qual. Life Outcomes 2017, 15, 51. [CrossRef]

27. Rudroff, T.; Fietsam, A.C.; Deters, J.R.; Bryant, A.D.; Kamholz, J. Post-COVID-19 Fatigue: Potential Contributing Factors. Brain Sci. 2020, 10, 1012. [CrossRef]

28. David, A.; Pelosi, A.; McDonald, E.; Stephens, D.; Ledger, D.; Rathbone, R.; Mann, A. Tired, weak, or in need of rest: Fatigue among general practice attenders. BMJ 1990, 301, 1199-1202. [CrossRef] 
29. Krogstad, H.; Loge, J.H.; Grotmol, K.S.; Kaasa, S.; Kiserud, C.E.; Salvesen, O.; Hjermstad, M.J. Symptoms in the general Norwegian adult population-Prevalence and associated factors. BMC Public Health 2020, 20, 988. [CrossRef] [PubMed]

30. Whitehead, L. The measurement of fatigue in chronic illness: A systematic review of unidimensional and multidimensional fatigue measures. J. Pain Symptom Manag. 2009, 37, 107-128. [CrossRef]

31. Tenforde, M.W.; Kim, S.S.; Lindsell, C.J.; Billig Rose, E.; Shapiro, N.I.; Files, D.C.; Gibbs, K.W.; Erickson, H.L.; Steingrub, J.S.; Smithline, H.A.; et al. Symptom Duration and Risk Factors for Delayed Return to Usual Health Among Outpatients with COVID-19 in a Multistate Health Care Systems Network-United States, March-June 2020. MMWR Morb. Mortal. Wkly. Rep. 2020, 69, 993-998. [CrossRef] [PubMed]

32. Goertz, Y.M.J.; Van Herck, M.; Delbressine, J.M.; Vaes, A.W.; Meys, R.; Machado, F.V.C.; Houben-Wilke, S.; Burtin, C.; Posthuma, R.; Franssen, F.M.E.; et al. Persistent symptoms 3 months after a SARS-CoV-2 infection: The post-COVID-19 syndrome? ERJ Open Res. 2020, 6, 00542-2020. [CrossRef] [PubMed]

33. Qi, R.; Chen, W.; Liu, S.; Thompson, P.M.; Zhang, L.J.; Xia, F.; Cheng, F.; Hong, A.; Surento, W.; Luo, S.; et al. Psychological morbidities and fatigue in patients with confirmed COVID-19 during disease outbreak: Prevalence and associated biopsychosocial risk factors. medRxiv 2020. [CrossRef]

34. van den Borst, B.; Peters, J.B.; Brink, M.; Schoon, Y.; Bleeker-Rovers, C.P.; Schers, H.; van Hees, H.W.H.; van Helvoort, H.; van den Boogaard, M.; van der Hoeven, H.; et al. Comprehensive health assessment three months after recovery from acute COVID-19. Clin. Infect. Dis. 2020. [CrossRef] [PubMed]

35. Wang, X.; Xu, H.; Jiang, H.; Wang, L.; Lu, C.; Wei, X.; Liu, J.; Xu, S. Clinical features and outcomes of discharged coronavirus disease 2019 patients: A prospective cohort study. QJM 2020, 113, 657-665. [CrossRef]

36. Metlay, J.P.; Fine, M.J.; Schulz, R.; Marrie, T.J.; Coley, C.M.; Kapoor, W.N.; Singer, D.E. Measuring symptomatic and functional recovery in patients with community-acquired pneumonia. J. Gen. Intern. Med. 1997, 12, 423-430. [CrossRef]

37. Lam, S.P.; Tsui, E.; Chan, K.S.; Lam, C.L.; So, H.P. The validity and reliability of the functional impairment checklist (FIC) in the evaluation of functional consequences of severe acute respiratory distress syndrome (SARS). Qual. Life Res. 2006, 15, $217-231$. [CrossRef] [PubMed]

38. Ahmed, H.; Patel, K.; Greenwood, D.C.; Halpin, S.; Lewthwaite, P.; Salawu, A.; Eyre, L.; Breen, A.; O'Connor, R.; Jones, A.; et al. Long-term clinical outcomes in survivors of severe acute respiratory syndrome and Middle East respiratory syndrome coronavirus outbreaks after hospitalisation or ICU admission: A systematic review and meta-analysis. J. Rehabil. Med. 2020, 52, jrm00063. [CrossRef]

39. Lam, M.H.; Wing, Y.K.; Yu, M.W.; Leung, C.M.; Ma, R.C.; Kong, A.P.; So, W.Y.; Fong, S.Y.; Lam, S.P. Mental morbidities and chronic fatigue in severe acute respiratory syndrome survivors: Long-term follow-up. Arch. Intern. Med. 2009, 169, 2142-2147. [CrossRef]

40. Abrahamsen, R.; Svendsen, M.V.; Henneberger, P.K.; Gundersen, G.F.; Torén, K.; Kongerud, J.; Fell, A.K. Non-response in a cross-sectional study of respiratory health in Norway. BMJ Open 2016, 6, e009912. [CrossRef]

41. Galea, S.; Tracy, M. Participation rates in epidemiologic studies. Ann. Epidemiol. 2007, 17, 643-653. [CrossRef] [PubMed]

42. Guo, Y.; Kopec, J.A.; Cibere, J.; Li, L.C.; Goldsmith, C.H. Population Survey Features and Response Rates: A Randomized Experiment. Am. J. Public Health 2016, 106, 1422-1426. [CrossRef]

43. Harrison, S.; Alderdice, F.; Henderson, J.; Redshaw, M.; Quigley, M.A. Trends in response rates and respondent characteristics in five National Maternity Surveys in England during 1995-2018. Arch. Public Health 2020, 78, 46. [CrossRef] [PubMed]

44. Blumenberg, C.; Barros, A.J.D. Response rate differences between web and alternative data collection methods for public health research: A systematic review of the literature. Int. J. Public Health 2018, 63, 765-773. [CrossRef]

45. Karatzias, T.; Shevlin, M.; Murphy, J.; McBride, O.; Ben-Ezra, M.; Bentall, R.P.; Vallieres, F.; Hyland, P. Posttraumatic Stress Symptoms and Associated Comorbidity During the COVID-19 Pandemic in Ireland: A Population-Based Study. J. Trauma Stress 2020, 33, 365-370. [CrossRef] [PubMed]

46. Ozamiz-Etxebarria, N.; Dosil-Santamaria, M.; Picaza-Gorrochategui, M.; Idoiaga-Mondragon, N. Stress, anxiety, and depression levels in the initial stage of the COVID-19 outbreak in a population sample in the northern Spain. Cad. Saude Publica 2020, 36, e00054020. [CrossRef]

47. Krishnamoorthy, Y.; Nagarajan, R.; Saya, G.K.; Menon, V. Prevalence of psychological morbidities among general population, healthcare workers and COVID-19 patients amidst the COVID-19 pandemic: A systematic review and meta-analysis. Psychiatry Res. 2020, 293, 113382. [CrossRef]

48. Shevlin, M.; Nolan, E.; Owczarek, M.; McBride, O.; Murphy, J.; Gibson Miller, J.; Hartman, T.K.; Levita, L.; Mason, L.; Martinez, A.P.; et al. COVID-19-related anxiety predicts somatic symptoms in the UK population. Br. J. Health Psychol. 2020, 25, 875-882. [CrossRef] [PubMed]

49. Elia, F.; Vallelonga, F. "Pandemic fatigue" or something worse? Recenti Prog. Med. 2020, 111, 788-789. [CrossRef] 